Preprints of the

Max Planck Institute for

Research on Collective Goods

Bonn 2013/17

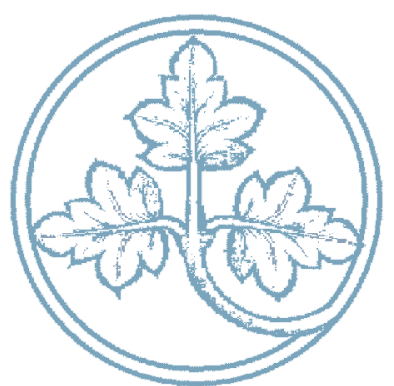

Win Shift Lose Stay -

An Experimental Test of

Non-Compete Clauses

Guido Bünstorf

Christoph Engel

Sven Fischer

Werner Güth

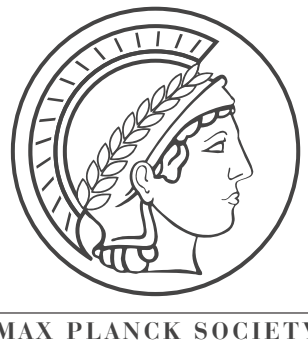




\section{Win Shift Lose Stay - An Experimental Test of Non-Compete Clauses}

Guido Bünstorf / Christoph Engel / Sven Fischer / Werner Güth

September 2013 


\title{
Win Shift Lose Stay - An Experimental Test of Non-Compete Clauses
}

\author{
Guido Bünstorf* Christoph Engel ${ }^{\dagger} \quad$ Sven Fischer ${ }^{\dagger \ddagger}$ \\ Werner Güth
}

September 19, 2013

\begin{abstract}
We experimentally test the effect of enforceable non-compete clauses on working efforts. The employee can invest into the probability of making a profitable innovation. After a successful innovation (Win) the employee may want to leave the firm (Shift) whereas after an innovation failure (Lose) he may remain (Stay). In the treatments with non-compete clause, but not in the baseline, the employer can prevent successful innovators from leaving the firm. With standard preferences, effort should be lower if the worker cannot leave the firm, except if compulsory compensation for having to stay is very high. By contrast we find no reduction in effort even if compensation is low. Employers anticipate the incentive problem and pay a higher wage which employees reciprocate by higher effort.

Keywords: labor relations, non compete clause, non compete covenant, reciprocity, fairness [JEL: L51, D21, J33, J38]
\end{abstract}

\section{Introduction}

Divorce is a messy affair, not only for couples. If an employee, or a trade agent for that matter, leaves her former principal, often acrimony is no less acute. Agents accuse principals of not having honored their efforts and suppressed their pioneering spirit. They invoke their human right to take up another position, or set up their own business. Principals, in turn, accuse agents of stealing customers, of appropriating human capital the principal has paid for, or of copying product or process innovations. If innovation is protected by effective intellectual property rights, the principal need not be concerned.

\footnotetext{
*University of Kassel, Nora-Platiel-Strasse 5, D-34109 Kassel, Germany, buenstorf@uni-kassel.de

${ }^{\dagger}$ Max Planck Institute for Research on Collective Goods, Kurt Schumacher Str. 10, 53113 Bonn, Germany, engel@coll.mpg.de; Sven Fischer: fischer@coll.mpg.de

${ }^{\ddagger}$ Max Planck Institute of Economics, Kahlaische Str. 10, 07745 Jena, Germany, gueth@econ.mpg.de; Sven Fischer: fischer@econ.mpg.de
} 
Yet often the product or process rely on tacit knowledge. Or the firm has legitimate reasons to keep the innovation as a trade secret rather than seek a patent or rely on their copyright.

Prevoyant employers try to protect themselves by a covenant preventing the employee from competing in the same or related industry, in case employment ends. Legal orders all over the world, and in the U.S. specifically, treat such covenants in very different ways (Ingram, 2002). Some states simply prohibit them, like California (Cal. Bus. \& Prof. Code $\S 16660$ ), North Dakota (N.D. Cent. Code 9-08-06), and historically Michigan, where the respective provision (Mich. Comp. Laws 445.761) was repealed in 1985 as part of a broader antitrust reform (Marx et al., 2009). Most jurisdictions, however, apply a rule of reason and investigate how onerous the constraint is for the agent, and how legitimate the reasons are for the principal (for detail, see Ingram, 2002). Frequently, the ban on competition is limited in time, e.g. for two years, and in space, e.g. to the state where the firm is established. Similar to the U.S., the laws on non-compete clauses (NCCs) differ across European countries.

Contracts between producers and independent sales agents give rise to a structurally equivalent problem. In practical terms, the distinction between a sales agent who is an employee, and a sales agent who legally is a firm, but just works for a single seller, is a very small one. The distinction is far more relevant in legal terms, particularly in the European Union, where contracts between producers and independent sales agents are subject to European antitrust law. In the EU, the ban on coordinating market behavior in principle not only covers horizontal constraints (i.e. cartels), but also vertical constraints (i.e. coordination between sellers and buyers). Since vertical constraints are much more likely to be normatively innocent, if not desirable, many of them are made legal per se by way of block exemption. Yet the pertinent regulation of the European Commission qualifies the exception to the ban. Covenants not to compete are illegal if their duration exceeds five years, or if the contracting partner promises not to manufacture, purchase or sell goods or services after the termination of the contract (Art. 5 (1) Commission Regulation No. 330/2010, OJ L 102/1).

A characteristic set of rules for non-compete clauses, which informs the setup of our model, is to be found in German law. Non-compete clauses are limited to a maximum of 2 years ( $\S 74$ a I $3 \mathrm{HGB})$. They are valid only if the principal pays half of the yearly salary (§ 74 II HGB).

The legal discourse is not all too specific about the rationale for allowing, prohibiting, or limiting covenants not to compete. A typical statement is to be found in a ruling of the German Supreme Court on Labor Affairs:

The legislator "recognizes the legitimate interest of the employer to rely on a covenant not to compete to protect herself against competition by her former employee and the resulting damage for the sustainability of her business. Yet the law in principle gives priority to the interest of the employee to decide upon her professional career after the termination of the employment relationship, and in particular to freely choose a new employer. This decision is in line with the constitutional protection of self-determination of employees, 
as stipulated by Art. 12 I Basic Law" (BAG 15.6.1993, BAGE 73, 229).

The legal provision is thus understood to strike a balance. The employer may protect herself. But only within limits, and against (substantial) compensation. This is backward looking, distributional reasoning. In contrast, in this paper, we adopt a forward looking perspective.

In a forward looking perspective, three potential effects of non-compete clauses are relevant. First, if the principal is protected by a non-compete clause, this increases her incentives to make relation specific investments (Garmaise, 2011). Second, noncompete clauses reduce labor mobility and thus welfare, and finally, non-compete clauses affect agents' effort. More specifically, as Kräkel and Sliwka (2009) show, whenever the principal would like to impose a NCC, expected employee returns from innovation diminish and, thus, optimal effort. In this paper, we bracket the first two arguments and focus on the latter. We do so since the effects on effort are largely overlooked by the legal and public, as well as scholarly discourse. We give a quick overlook of the existing literature on non compete covenants in general in the following section.

The literature that directly speaks to our research question is very small. Marx et al. (2009) find no evidence suggesting that the Michigan reform decreased overall patenting rates (which could be seen as a proxy of employee effort) of the state's inventors, but more direct individual-level results are lacking. In the model by Kräkel and Sliwka (2009), if an innovation occurs, an employer is ex-post always better off with a non-compete clause. However, ex-ante incentives for the worker to exert effort are higher without a clause due to the prospect of a high retention offer in case of a successful innovation. Thus, whether or not the employer would like to impose a non-compete clause depends on the relative importance of efforts. Kräkel and Sliwka (2009) rely on a fairly complex principal agent game and solve it assuming common knowledge of rationality based on (monetary) opportunism. Analyzing their model with other regarding and risk preferences renders the model very complex, e.g. when assuming that hey are only privately known.

Our research question is difficult to study in the field. Although in the United States of America, some states allow and others forbid non-compete clauses, these states crucially differ in other relevant legislature and industry structure. Moreover, in the real world, individual working efforts are not verifiable and success or failure of innovation is not clearly defined, especially in cases where non-compete clauses are most relevant. Suppose for example that a firm wants to keep an innovation a trade secret. This is an exemplary situation calling for the enforcement of a non-compete clause. Without a patent, it would be easy for an employee to make use of the knowledge she acquired. However, an outside researcher will never learn that an innovation actually was made. Similarly, wage and profit data, and compensation in case a non-compete clause is invoked, are also difficult to get hold of. Despite a possible loss of realism, we therefore study the effect of a non-compete clause under the more controlled conditions of the laboratory. To the best of our knowledge no such study has been done so far.

We translate the relationship between employer and employee into a simple sequential game, where we compare behavior in a Baseline without NCC to that in two treatments 
with a NCC. ${ }^{1}$ Two individuals are exogenously matched. The principal is free to set a positive wage. Knowing the wage, the agent decides how much effort to invest. The higher her effort the more likely a profitable innovation occurs. Her effort always remains private information. If the investment into the innovation is successful, the agent may leave the firm. Instead she can ask for a retention offer which the employer can only accept or reject. Our three games only differ in the outside option of this bargaining stage. If she leaves in the Baseline, both compete on the market and make a small profit. In this case, joint profits are substantially smaller than if she had stayed, as the employer loses her monopoly power. In the two treatments with NCC, the agent receives a commonly known and predefined compensation and is successfully prevented from competing on the market. In the High treatment, if renegotiations fail, her compensation is the same as the renegotiation outcome in the Baseline under the standard assumptions of selfishness and common knowledge of rationality. In the Low treatment, her compensation is considerably below this benchmark. By making sure that the two treatments and the Baseline only differ in one respect, namely the outside option in the renegotiation stage, we can directly compare behavior between these different settings.

If we make standard assumptions, effort and profits are the same in the Baseline and in treatment High, but lower in treatment Low. However, if it is possible that principals hold other regarding preferences, incentives to invest effort are reduced in the Baseline since the agent cannot be sure to extract the entire rent from the principal. We therefore predict that effort is highest in the treatment with High compensation, followed by the Baseline and treatment Low. If the principal expects the agent to be loss averse, she pays a positive wage. Assuming reciprocal agents, the principal also pays a positive wage if she wants to induce the agent to exert higher effort.

More specifically, in the Baseline we expect that the employer due to entitlement would be unwilling to accept that the agent reaps as much of the surplus as he possibly can. After all, the invention the agent wishes to exploit was made in the name of, and funded by, the firm. We, furthermore, assume that agents are reciprocal (and principals correctly anticipate), based on experimental evidence such as in the gift exchange or investment game (starting with Fehr et al. (1993) and Berg et al. (1995), for a survey, see Cooper and Kagel (2013)).

Our experiment yields a clear message: introducing a non-compete clause does not affect effort and therefore leaves success unaffected. This even holds if the legally mandated compensation is low in case the clause is enforced. In this case employers pay a higher upfront wage which, like in a gift exchange game, increases effort. We observe strong reciprocal patterns not only on behalf of wages and effort, but also in how renegotiation demands depend on received wages and invested effort.

In our setting, enforcing non-compete clauses is efficiency enhancing. If mandated compensation is low, employers win and employees do not lose. If mandated compensation is high, employees win and employers do not lose. There is no significant effect on innovation success.

${ }^{1}$ Allowing the principal to endogenously impose a NCC may reveal that the principal does not trust his agent. This is avoided by exogenously imposing it. 
Choosing a policy it is not the same as introducing or abolishing it. Legal reform affects experienced actors. To see in which ways experience matters, we expose participants to a regime change. For the parties involved, abolishing the enforcement of non-compete clauses has clear adverse effects. Whether compensation is high or low, total profit is reduced. Yet effort increases if the clause is no longer enforced and if, previously, compensation was low. The effect of newly introducing non-compete clauses is less pronounced. There is only a small positive effect on total profit if compensation is high. Yet newly protecting non-compete clauses does definitely not have a detrimental effect.

The remainder of the paper is organized as follows: section 2 gives a quick overview over related literature, section 3 introduces the design of the experimental game. In section 4 we make point predictions under standard assumptions and formulate our behavioral hypotheses, before we analyse our experimental data in section 5 . Section 6 concludes with a discussion of our main results and their external relevance.

\section{Other Related Literature}

The literature has chiefly been interested in an effect of non-compete clauses that we bracket, the effect on labor mobility. Gilson (1999) first suggested that the nonenforceability of non-compete clauses enhanced labor mobility in California, which in turn may have contributed to Silicon Valley's development into being the world's leading high-technology cluster. This conjecture has motivated subsequent studies exploring the potential trade-off between employers' incentives to invest in employees' human capital formation and positive externalities emanating from the mobility of highly skilled workers and its repercussions on industrial dynamics (Fallick et al., 2006; Franco and Mitchell, 2008). Empirical research based on field data provides substantial (albeit indirect) evidence indicating that non-compete clauses are effective constraints to employee mobility. Marx et al. (2009) use patent data to study how the legal change in Michigan affected the likelihood of inventors switching employers within the state. Relative to other U.S. states where non-compete clauses remained illegal, Michigan experienced a significantly lower increase in intra-state inventor mobility after the reform of 1985 . This finding is corroborated by geographic patterns of citations to U.S. university patents (Belenzon and Schankerman, 2012). While U.S. state borders generally constrain knowledge flows (as measured by patent citations), the effect is significantly weaker for post-reform Michigan, suggesting a decrease in intra-state knowledge flows due to restricted employee mobility.

Garmaise (2011) studies effects of non-compete clauses on top-level executives of publicly traded U.S. firms. He shows that increased enforceability of non-compete clauses is associated with decreased rates of mobility and with lower, more salary based compensation. This is interpreted as supporting a model in which both employers and employees can make non-contractible human capital investments, and where the enforceability of non-compete clauses shifts incentives to invest into human capital from employees to employers.

Further results by Stuart and Sorenson (2003) for the U.S. biotechnology industry indicate that non-compete clauses also reduce rates of spin-off entrepreneurship. Samila 
and Sorenson (2011) likewise find that the regional availability of venture capital is more strongly associated with patent counts, new firm formation and employment growth in U.S. states where non-compete clauses are not enforceable. They attribute these results to spin-off entrepreneurship as well as positive effects of employee mobility on knowledge spillovers and the quality of employee-employer matching. A quantitative analysis of U.S. appellate courts' willingness to enforce non-compete clauses found two major reasons for granting protection: the employee had access to a confidential customer list, or to a trade secret. The narrower the temporal and the geographic scope of the clause, the more likely it was enforced. Public interest considerations were also relevant (Whitmore, 1989).

\section{Design}

In our experiment, an employer or principal $P$ and an employee or agent $A$ interact once. By way of illustration, in this section we look at and speak of innovation. Yet by analogy the design also captures a company's sales representative trying to enlarge its customer base. Our Baseline differs from typical experimental settings in labor economics in two respects: first, whether higher effort of the agent increases the principal's profit is uncertain; second, if effort leads to success, there is renegotiation between the parties. The first feature captures the random nature of innovation and, furthermore, keeps effort private information. The second feature addresses the bargaining power of a successful employee who, in the absence of a non-compete clause, may not be prevented from taking the new knowledge to another employer, or to set up her own business.

Specifically, at the beginning of the game, $P$ unilaterally chooses wage $w \in[0, W]$. We thus abstract from hiring competition and assume that the parties have already entered an employment contract. Knowing $w$, agent $A$ chooses effort $e \in[1, E]$; thus at least minimum effort is enforceable. Nature decides whether the innovation is successful with probability $p=\sqrt{e} / \rho$, with $\rho>\sqrt{E}$. If the innovation is not successful, the game ends and payoffs are $V_{P}=\pi-w$ for $P$, and $V_{A}=w-e$ for $A$, where $\pi$ represents market profit without the innovation. If the innovation is successful, both can renegotiate. $A$ can ask for a retention offer $v \in[0, \Pi]$. $P$ may only accept or reject. This ultimatum-power of $A$ reflects that, in the absence of a non-compete clause, the employee is free to leave the firm and to exploit the innovation. $\Pi$ is market profit given the innovation was successful and there is no competition, which is why we assume $\pi<\Pi$. If $P$ accepts, payoffs are $V_{P}=\Pi-w-v$ and $V_{A}=w+v-e$. If $P$ rejects, $A$ leaves the firm and competes with $P$ in the market. Payoffs then equal $V_{P}=\alpha \Pi-w$ and $V_{A}=\alpha \Pi+w-e$, with $\alpha<1 / 2$ capturing the difference between monopoly and market competition.

We have two treatments with an exogenously imposed non-compete clause. These two differ in the amount $k$ that $A$ receives in compensation. This amount is either Low or High. If the innovation fails, the game does not differ from the Baseline. If the innovation is successful, the renegotiation protocol remains the same. The only difference is in the payoffs if renegotiations fail which now are given by $V_{P}=\Pi-w-k$ and $V_{A}=w+k-e$.

In view of the multiple parameters a systematic analysis of the effects when varying them, for example individually, seems futile. Instead we focus on the crucial parameter $k$, the compulsory compensation under a NCC. For the other parameters wee would 


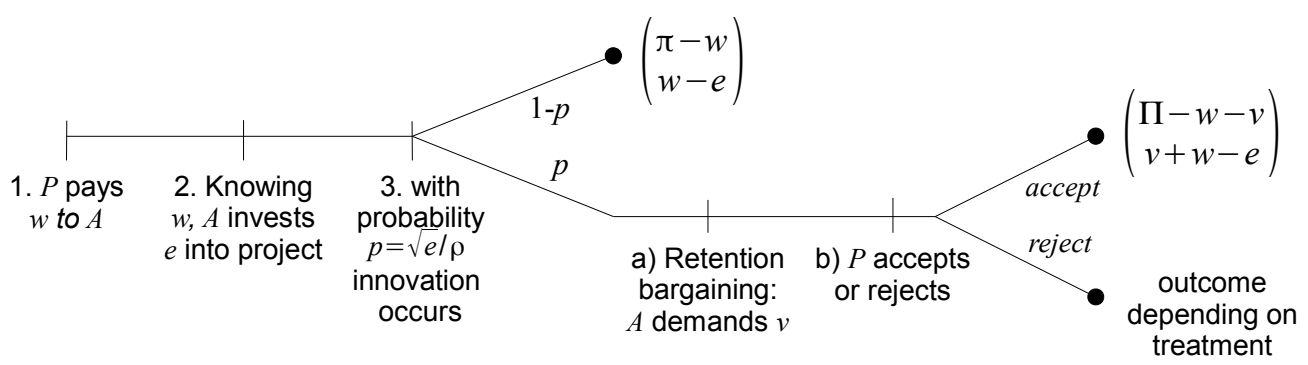

Figure 1: Timeline of the Experimental Game

expect similar qualitative effects as for the benchmark, based on common opportunism.

To investigate whether effects are stable over time, participants play the stage game eight announced times with varying partners. Roles are kept constant throughout and rematching is done under a stranger protocol. We assign participants to matching groups of 16 ( $8 \mathrm{P}$ and $8 \mathrm{~A}$ ), but do not tell them that matching groups are limited. This procedure guarantees independent observations, without inducing participants to second guess group composition (see, for example Charness, 2000; Montero et al., 2008). If there is a non-compete clause, from period to period compensation $k$ alternates between being Low or High. Between matching groups, we counterbalance compensation in the first period (with a non-compete clause).

In the interest of investigating the effects of a regime change, after the end of period 8 there is a surprise restart. ${ }^{2}$ Participants who played the Baseline in the first phase are now assigned to an environment with an enforceable non-compete clause, and randomly determined size of compensation. Participants who were in a context with a non-compete clause now play the Baseline. The second phase of the experiment also lasts eight announced periods. Roles and, unbeknownst to participants, matching groups are kept constant throughout.

The experiment was conducted in the lab of the Max Planck Institute of Economics in Jena, Germany. The experiment was implemented in zTree (Fischbacher, 2007). Participants were invited with the software ORSEE (Greiner, 2004) and had to take a quiz to make sure they had understood the instructions. We had 256 student participants of various majors, $46.39 \%$ female, mean age 23.58. Participants on average earned $€ 20.39$ (26.44 USD), $€ 22.46$ for principals and $€ 18.38$ for agents The experiment lasted on average around two and a half hours, including admission and payment.

\footnotetext{
${ }^{2}$ Participants know from the beginning that the experiment has several parts, but they do not know the design of future parts.
} 


\section{Hypotheses}

Before we present our experiment in more detail we want to look closer at what behavior one may expect. We first derive predictions assuming rational participants who hold standard, opportunistic and risk neutral preferences, and that all of this is commonly known. We look for the unique sequentially rational equilibrium (Kreps and Wilson, 1982). If the innovation is successful, $P$ accepts if $v \leq(1-\alpha) \Pi$. Consequently $A$ demands $v=(1-\alpha) \Pi$ and expects to earn

$$
E\left[V_{A}\right]=\frac{\sqrt{e}}{\rho}(1-\alpha) \Pi+w-e
$$

which she maximizes by investing (for relevant parameterizations) optimal effort ${ }^{3}$

$$
e^{*}=\frac{(1-\alpha)^{2} \Pi^{2}}{4 \rho^{2}} .
$$

As the initial wage is merely a gift, the principal sets optimal wage $w^{*}=0$.

The game has multiple other equilibria. For instance, the bargaining stage after a successful innovation has a continuum of equilibria, each characterized by A demanding some $v^{+}$, with $\alpha \Pi<v^{+}<(1-\alpha) \Pi$, and $P$ accepting any $v \leq v^{+}$. There also exist equilibria with positive $w .{ }^{4}$ Yet, none of these equilibria are sequentially rational. Still, this multiplicity of equilibria is an important characteristic of our game, as it reflects the often much more complex or even indetermined nature of real world interactions that motivate our study.

If there is a non-compete clause, the size of $k$ affects $P$ 's willingness to accept $v$. She accepts any $v \leq k$, and rejects otherwise. This means that $(1-\alpha) \Pi$ in $(1)$ is replaced by $k$ and, thus, optimal effort changes to

$$
e^{*}=\frac{k^{2}}{4 \rho^{2}} \text {. }
$$

While higher $k$ increases effort, it also reduces the profit of the principal in case of success. It is easy to show that the principal would see his expected return maximized for

$$
k_{P}^{*}=\frac{\Pi-\pi}{2} .
$$

The agent on the other hand always prefers a larger $k$ whereas efficiency is maximized for $k=\Pi-\pi$. The level of $k$ is therefore critical for predictions. However, there are some natural limits. Whenever $k$ exceeds what the agent could at most demand in the absence of a NCC, then the principal would never invoke the NCC and rather pay the employee

\footnotetext{
${ }^{3}$ Our parametrization guarantees $0<e^{*}<E$.

${ }^{4}$ Suppose, for example, that $A$ exerts optimal effort $e^{*}$, demands some $v>(1-\alpha) \Pi$ if $w<w^{+}$, and $v=(1-\alpha) \Pi$ if $w \geq w^{+}$. Then $P$ pays $w^{+}$, accepts if $v \leq(1-\alpha) \Pi$, and rejects otherwise. This strategy profile constitutes an equilibrium as unilateral deviation leaves both with at most as much as before.
} 
to stay in the firm. Thus a legal requirement of a very large $k$ is equivalent to the absence of a NCC. On the other hand, a very small $k$ is likely to be unconstitutional in societies that grant fundamental human rights to workers. A denial of freedom of movement and choice of employment can only be ruled constitutional if it is compensated adequately.

These two natural limits define our parametrization. We compare two very different levels of compensation $k$. In the treatment with a High compensation, in the unique sequentially rational equilibrium, the principal only just prefers the non-compete clause rather than $A$ leaving the firm, i.e. $k \leq(1-\alpha) \Pi$. Furthermore, $A$ invests the same effort as in the Baseline. In the treatment with a Low statuary compensation on the other hand, the agent expects to earn about a third of what he could earn in the Baseline without NCC. It is unlikely that any lower compensation requirement could withstand legal challenge. Furthermore, a lower $k$ is not in the interest of the economy, as the resulting equilibrium effort is substantially lower.

More specifically, in the experiment, we set $\Pi=18,000, \pi=4,000, E=6,000, \rho=100$, $\alpha=1 / 3, k_{\text {Low }}=7,000$, and $k_{\text {High }}=12,000$. These parameters fulfill a further condition that makes our experiment meaningful: Incentives to exert effort are suboptimal since $\pi<\alpha \Pi$. Treatment High represents the highest possible relevant level of $k$, whereas in treatment Low we use a lower boundary. Table 1 shows the resulting point predictions under the standard assumptions. This setup and parameterization leads to the following predictions:

Prediction 1 If all agents are rational, have opportunistic preferences and this is common knowledge, we expect

a) zero wages

b) less effort (and success) in treatment Low $^{5}$

c) successful renegotiation, irrespective of treatment

d) lower renegotiation demands $v$ in treatment $L o w^{5}$

e) lower total profit in $L o w^{5}$

f) identical effort and outcomes in the Baseline and treatment High.

Under standard assumptions there are therefore no differences in outcomes between the Baseline and treatment High. Yet, based on existing experimental evidence we expect treatment differences due to social preferences and uncertainty about them. More specifically, the retention bargaining stage may have multiple equilibria, with the one above also satisfying sequential rationality. As already indicated in the Introduction we expect different other regarding concerns of principal and agent. Whereas the former is more fairness concerned, the latter is more driven by reciprocity concerns. A small chance of the principal holding non-opportunistic preferences suffices to introduce strategic uncertainty and render other equilibria focal, equilibria with less payoff for the

\footnotetext{
${ }^{5}$ Compared to the other settings.
} 
Table 1: Point Predictions Assuming Standard Preferences

\begin{tabular}{lccc}
\hline & Baseline & Low & High \\
\hline$e^{*}$ & 3,600 & 1,225 & 3,600 \\
$p$ & 0.60 & 0.35 & 0.60 \\
$v$ & 12,000 & $\geq 7,000$ & $\geq 12,000$ \\
$V_{A}$ success & 8,400 & 5,775 & 8,400 \\
$V_{A}$ failure & $-3,600$ & $-1,225$ & $-3,600$ \\
$E\left[V_{A}\right]$ & 3,600 & 1,225 & 3,600 \\
$V_{P}$ success & 6,000 & 11,000 & 6,000 \\
$V_{P}$ failure & 4,000 & 4,000 & 4,000 \\
$E\left[V_{P}\right]$ & 5,200 & 6,450 & 5,200 \\
$E\left[V_{A}\right]+E\left[V_{P}\right]$ & 8,800 & 7,675 & 8,800 \\
\hline
\end{tabular}

agent. ${ }^{6}$ In response, the agent will reduce effort, compared to the benchmark assuming preferences to be common knowledge. ${ }^{7}$ By contrast, in the High treatment the agent expects the same amount as the one predicted in the Baseline, this time, however, with certainty due to an exogenous rule. Thus, incentives to invest effort are lower in the Baseline than in treatment High.

Hypothesis 1 When principals hold social preferences, in comparison to the benchmark solutions,

a) agents make lower demands in the renegotiation in the Baseline

b) agents invest less effort in the Baseline

c) Principals reject high demands in the renegotiation stage.

and, furthermore,

Hypothesis 2 Agents invest less effort in the Baseline than in treatment High.

In equilibrium, wage $w$ is zero. For a series of reasons, principals might want to pay a positive wage. Two reasons hold irrespective of treatment. With any positive investment $e$, the agent makes a loss if the innovation fails. ${ }^{8}$ Principals could also hope that agents reciprocate a high wage by higher effort, as for example in gift exchange experiments (for an overview see Brandts and Charness 2004).

\footnotetext{
${ }^{6}$ See experimental results on ultimatum bargaining as, for example, summarized in Camerer (2003).

${ }^{7}$ Note that if a selfish principal could ex ante restrict the agent's bargaining power, he would like to do so, as the increase in payoff in case of success outweighs the loss in effort.

${ }^{8}$ Loss aversion (see Tversky and Kahneman, 1992) could therefore deter agents from investing optimal effort. A positive wage (partly) insures the agent against the risk of loss.
} 
The gift exchange motive is independent of variations in treatment or $k$. The problem of loss aversion, however is stronger in the Baseline and treatment High where optimal effort, and therefore possible losses, are higher than in Low. This suggests

Hypothesis 3 Due to reciprocity and (expected) loss aversion (of the agent),

a) Principals pay positive wages

b) Principals pay lower wages in the Low treatment

c) Effort increases in the wage.

However, in treatment Low there is another possible effect. A fair minded principal may want to signal her willingness to concede more to the agent in case of a successful innovation in order to induce higher effort. Thus, by paying a high wage, she induces effort in two ways. First via creating positive reciprocity and second by indicating that effort will pay off. While it is unclear whether the previous effect from hypothesis $3 \mathrm{~b}$ outweighs this positive effect or not, we alternatively expect

Hypothesis 4 A fair minded principal can signal her intention to leave more to the agent in case of a successful innovation by paying a high $w$. Contradicting hypothesis $3 \mathrm{~b}$ we therefore expect higher wages $w$ in treatment Low than according to the benchmark.

Finally, it is possible that agents also show positive reciprocity in the renegotiation stage.

Hypothesis 5 Agents behave reciprocally in the renegotiation stage and demand less the higher the wage.

\section{Results}

We first report treatment effects from the initial eight periods, before we take a closer look at dynamics. We thus first compare outcomes for participants who have not had experiences with the opposite regime. From a policy perspective, this is analogous to comparing two jurisdictions, one that honors non-compete clauses, and another where they are illegal. Since our experiment has been triggered by the ongoing policy debate over the desirability of non-compete clauses, we organize results by their policy relevance. Unless mentioned otherwise we rely on a significance threshold of $5 \%$ throughout the following analysis.

\subsection{Effort and Wages}

Ultimately, policymakers will be most interested in total welfare. For society at large, the most important concern is that non-compete clauses might stifle agent effort and thereby reduce innovation. The left barplot in Figure 2 shows a first, striking finding. Against theoretical expectations, imposing a non-compete clause has no significant effect on effort. Effort in the Baseline does not differ significantly from that in either treatment, 

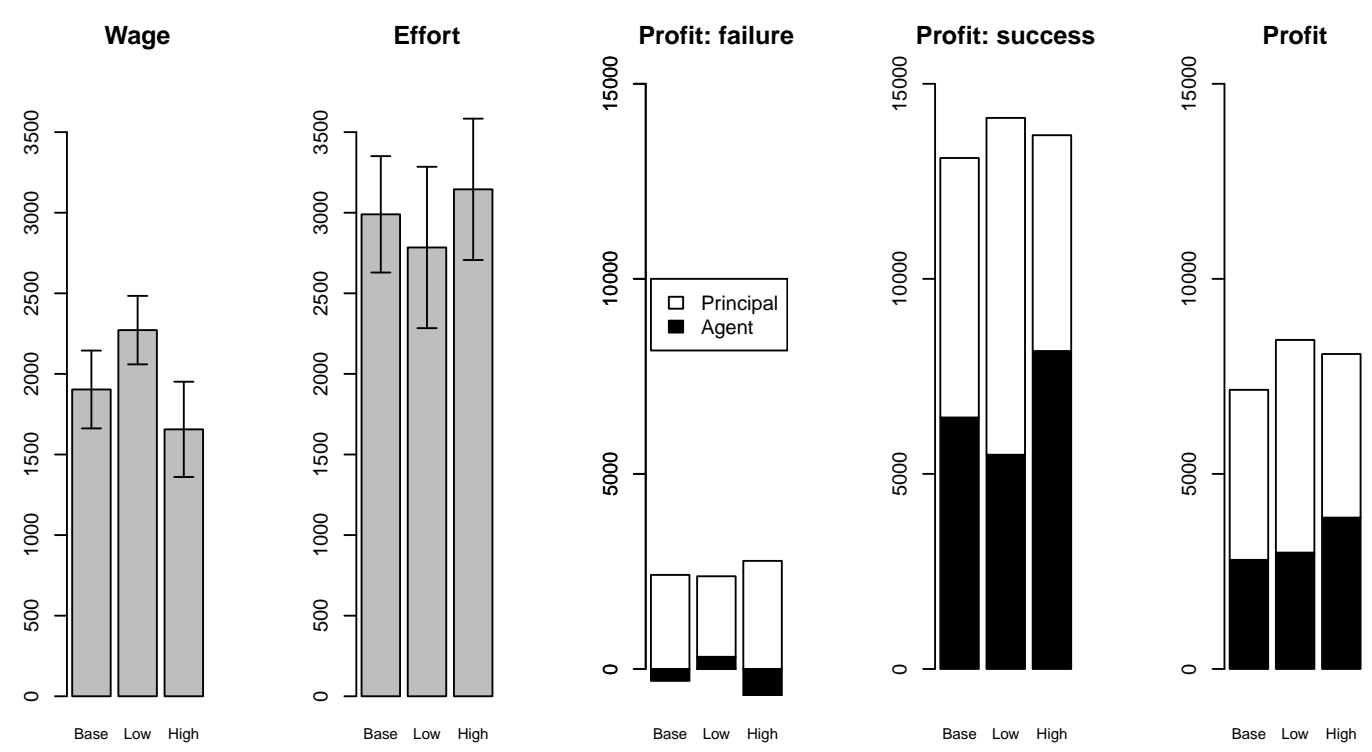

Figure 2: Main Effects, Inexperienced Participants

Note: Data from periods 1 to 8 only. $90 \%$ Confidence intervals based on distribution of matching group averages.

neither non-parametrically nor parametrically. ${ }^{9}$ There is, however, some indication that effort in High is significantly higher than in Low (one-sided signed rank test: $p=0.0618$, mixed effects panel estimation: $p=0.0716)$. We therefore reject prediction $1 \mathrm{~b}$ derived from standard theory and Hypothesis 2, predicting less effort in the Baseline.

Result 1 If agents are prevented from leaving the firm, this does neither increase nor reduce effort, even if compensation paid to agents is low.

A reason for this might be that agents focus on successful innovation and choose high effort to achieve a favorable outcome. How does actual effort compare to the benchmarks? Signrank tests over means of matching groups reject all point predictions. Effort is lower than predicted in the Baseline $(N=8, p=.0499)$ (confirming Hypothesis $3 \mathrm{~b})$ and in treatment High $(N=8, p=.0499)$, and it is higher than predicted in treatment $\operatorname{Low}(N=8, p=.0177)$. Also, in all three settings, effort is significantly below the efficient effort of 4900 tokens $(p<.05)$.

The next piece of explanation follows from the barplot of average wages in Figure 2. In the Baseline and in the two treatments, principals pay sizeable wages (signrank tests

\footnotetext{
${ }^{9}$ Unless mentioned otherwise, all non-parametric tests in this paper are based on the distribution of averages over all periods per matching group. For parametric estimations, we control for the panel structure by including a random effect per individual nested in a random effect on the group level. Unless mentioned otherwise all tests are two-sided.
} 
reject the null hypothesis that wages are zero for all three settings at $\mathrm{N}=8, \mathrm{p}=.0117$ ). Yet wages are highest in the Low treatment (Mann Whitney test, $\mathrm{N}=16$, comparing Baseline with Low, $\mathrm{p}=.0587$; comparing Low with High, $\mathrm{p}=.0173$ ). By contrast, there is no significant difference in wages between the Baseline and High $(\mathrm{p}=.1415)$.

In Hypothesis 3c we expected a positive correlation between wage and effort. The regression of Table 2 shows that this is indeed the case. There is a strong, and significant, positive effect of the wage. Note the significant and strong interaction between wage and treatment Low. In treatment Low effort on average increases by 0.46 for every increase in $w$, which is an entire $36 \%$ higher than the 0.29 in the Baseline. Thus, agents react stronger to changes in the wage if they are in a weaker position. However note that, conditional on wages, effort in treatment Low is significantly lower than in the Baseline. This shows the critical role of the wage. Through paying a substantial wage, principals counteract the detrimental effect of Low compensation on effort (see also Hypothesis 4).

Table 2: Effect of Wage on Effort, Inexperienced Participants

\begin{tabular}{rcc}
\hline effort & coef. & s.e. \\
\hline cons & $2137.46^{* * *}$ & $(248.61)$ \\
Low & $-694.42^{* *}$ & $(308.61)$ \\
High & 185.51 & $(294.29)$ \\
wage & $0.29^{* * *}$ & $(0.039)$ \\
Low $\times$ wage & $0.17^{* *}$ & $(0.068)$ \\
High $\times$ wage & 0.02 & $(0.065)$ \\
\hline$N$ & \multicolumn{2}{c}{1024} \\
$p$ model & \multicolumn{2}{c}{$<0.001$}
\end{tabular}

Note: Mixed effects linear ML estimation with random effect per subject nested in matching group effect. Data from periods 1 to 8 only. Regressions include control dummies for periods 2 to 8 (not reported). ${ }^{*} p<0.1,{ }^{* *} p<0.05,{ }^{* * *} p<0.01$

Result 2 Principals pay positive wages. The higher the wage, the higher agents' effort. Wages are more effective in inducing effort if statutory compensation for success is Low.

We thus reject the first two statements of Prediction 1 (zero wages throughout, less effort in treatment Low), based on the assumption of agents holding standard preferences. If we look at our more behavioral expectations, we find support for the first statement of Hypothesis 3 (positive wages throughout) but reject the second (lower wages in Low). This latter rejection means we find support for the opposing Hypothesis 4: it appears that principals try to counter the low incentives to exert effort in treatment Low by paying higher wages. We argued that this works, as it signals the principal's intention to concede higher retention offers to the agent in case of success. Before we can make a concluding statement with respect to Hypothesis 4, however, we need to analyse the final bargaining stage. 


\subsection{Final Payoffs}

From a policy perspective, it is also relevant how total payoffs and their distribution are affected. Figure 2 shows that total profits are highest in treatment Low, followed by High and the Baseline. All these differences are significant, Table 3 summarizes the $p$-values from non-parametric tests. ${ }^{10}$

If we look at individual payoffs, the ranking becomes rather different. Principals earn considerably and significantly more in Low than in either High or the Baseline, where in turn they earn about the same. Agents on the other hand earn significantly more in High than in either Low or the Baseline, where in turn they earn about the same. As efforts did not differ significantly between the treatments and the Baseline, the reason for the worse performance of the latter must come from more conflict in the bargaining stage, something we will analyze in more detail later.

Result 3 Payoffs are higher in the treatments with NCC. Principals earn most when compensation is Low, agents when it is High.

Table 3: Test Results for Comparisons of Profits

\begin{tabular}{rccc}
\hline & Base vs. Low & Base vs. High & Low vs. High \\
\hline Total Profit & $\mathbf{0 . 0 7 5 4}$ & $\mathbf{0 . 0 7 4 2}$ & $\mathbf{0 . 0 9 2 9}$ \\
Agent & 0.9164 & $\mathbf{0 . 0 4 6 0}$ & $\mathbf{0 . 0 1 7 3}$ \\
Principal & $\mathbf{0 . 0 1 5 7}$ & 0.7527 & $\mathbf{0 . 0 1 1 7}$ \\
\hline Note: Reported values are $p$-values from two-sided rank-sum tests (com- \\
parisons to Baseline) and signed-rank tests (Low vs. High).
\end{tabular}

Figure 2 shows profits conditioned on success, treatment and role. Due to the high wages, agents make only small losses in the Baseline and in treatment High in case the innovation fails. For a Low compensation, wages are high enough to outweigh the losses on average. If the project fails, agents earn significantly more than predicted, and principals earn considerably less (sign-rank tests compared to prediction, all $p \leq 0.0117$ ). This is yet another piece of evidence that through the wage, principals insure agents against the risk of project failure.

If the project is successful, in the Baseline agents earn significantly less than standard theory predicts, and principals earn significantly more. Effectively, the difference in earnings predicted by theory vanishes. If non-compete clauses are honored, agent earnings are not significantly different from theoretical predictions. Yet principals earn significantly less than predicted, irrespective of treatment (sign-rank tests compared to prediction, all $p \leq 0.0687$ ).

\footnotetext{
${ }^{10}$ Note that these results are in line with our results on efforts. Total efficiency in the two treatments is entirely defined by effort.
} 


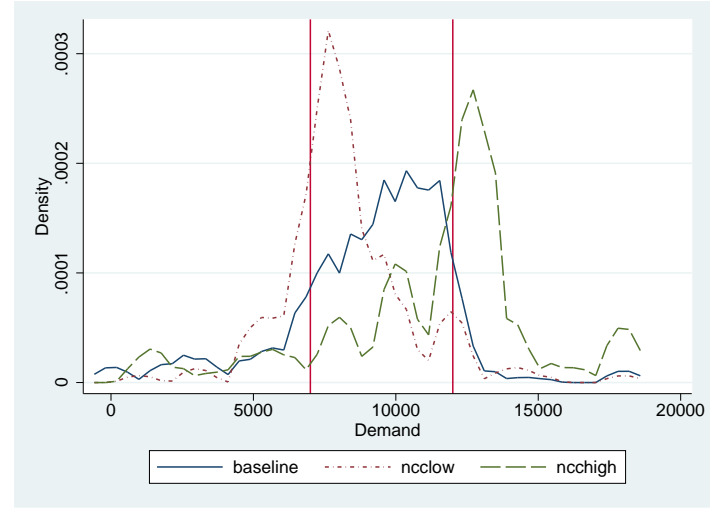

Figure 3: Demands

Note: Red line: theoretical prediction. Epanechnikov Kernel, bandwidth $=400$

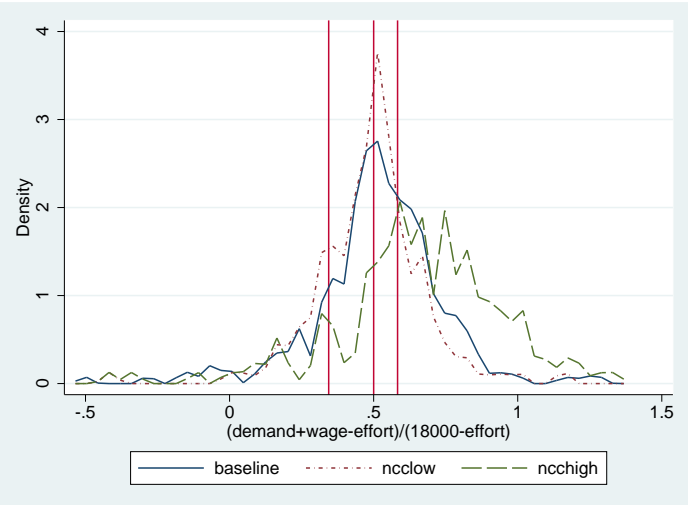

Figure 4: Demanded Share of Surplus Note: Epanechnikov Kernel, bandwidth $=0.2$

\subsection{Retention Bargaining}

With the main issues of policy relevance being covered, let us now look into more detail how behaviour unfolds. The negotiation protocol gives agents ultimatum power, with outside options differing considerably between treatments. Only in the Baseline, agreement results in efficiency gains and the outside option is rather equal. In treatment Low the outside option favors the principal, and vice versa in High. Figure 3 shows that in the Baseline agents make fairly cautious demands. Almost all of them are below the theoretical prediction of 12,000 tokens. By contrast, if there is a non-compete clause, the majority of agents demand more than the guaranteed compensation. Comparisons show that agents demand most in treatment High, and least in treatment Low. ${ }^{11}$

With respect to fairness concerns we need to look at how these demands compare to a benchmark. The most reasonable benchmark depends on the wage and invested effort. Figure 4 shows the distributions of the shares of the entire surplus agents demand overall, i.e. taking into account the wage they already received and the invested effort. Remember that effort is private information and agents could use that to their advantage. However, strikingly in the Baseline and in treatment Low where the outside option is either relatively fair or the agent receives less in conflict, demanded shares are centered on the equal split and do not differ significantly from it according to signrank tests. In treatment High, however, where the agent is ahead if the principal rejects, demanded shares are considerably above 0.5 (signrank test, $\mathrm{p}=0.0089$ ) and significantly higher than in the other cases. We must also compare demanded shares with the benchmark cases. In the Baseline, shares are significantly smaller than the benchmark (signrank test $\mathrm{p}=0.0179$ ) and in the treatments they are significantly larger (signrank test Low $\mathrm{p}=0.0059 ;$ High $\mathrm{p}=0.0087$ ).

\footnotetext{
${ }^{11}$ All treatment comparisons are significant: Baseline vs. Low, Mann Whitney, $N=16, p=.0567$; Baseline vs. High, $N=16, p=.0016$; Low vs. High, signrank test, $N=8, p=.0117)$.
} 
Result 4 Compared to equilibrium shares, agents demand less in the Baseline but more in the main treatments.

But how do final demands depend on the history of play? The regressions in Table 4 show that demands of agents in case of success decrease in the wage they received. As model (2) shows, this effect is the same in all treatments including treatment Low (see also the joint hypothesis tests in the footnote of the table). Agents are not more sensitive to the size of the wage if the compensation scheme favors the principal. In all treatments, however, demands decrease in wage by significantly less than one (Wald tests, $p<.001)$.

Table 4: Explaining Renegotiation Demands, Inexperienced Subjects

\begin{tabular}{rcc}
\hline demand & $(1)$ & $(2)$ \\
\hline Low & $-781.641^{* *}$ & -593.572 \\
High & $2152.843^{* * *}$ & $2101.854^{* * *}$ \\
wage & $-0.246^{* * *}$ & $-0.238^{* *}$ \\
Low $\times$ wage & & -0.073 \\
High $\times$ wage & & 0.027 \\
cons & $8021.256^{* * *}$ & $7987.925^{* * *}$ \\
\hline all models: & \multicolumn{2}{r}{$N=498 ; p<0.001$}
\end{tabular}

Note: Mixed effects linear ML estimation with random effect per subject nested in matching group effect. Data from periods 1 to 8 only. Regressions include control dummies for periods 2 to 8 (not reported). ${ }^{*} p<0.1,{ }^{* *} p<0.05,{ }^{* * *} p<0.01$. Wald tests: Model (2): wage + Low $\times$ wage $=0 p=0.020^{* *}$; wage $+H i g h \times$ wage $=0 p=0.067^{*}$.

Result 5 Demands decline equally strong in the received wage in all three settings.

The threat of an efficiency loss in case of a rejection of $v$ in the Baseline is reflected in the acceptance rates. With $89.36 \%$ considerably more renegotiation demands are accepted in the Baseline, compared to only $31.82 \%$ and $46.96 \%$ in the treatment with Low and High compensation, respectively. Both comparisons with the Baseline are significant (Mann Whitney, $\mathrm{N}=16, \mathrm{p}=.0008$ ).

In Table 5 we analyze the acceptance of renegotiation demands. Model (1) confirms our non-parametric result that overall acceptance in the treatments with NCC are significantly smaller. ${ }^{12}$ As model (2) shows, these differences in the base rate of acceptance are due to differences in demands. ${ }^{13}$ Acceptance decreases significantly in demands in

\footnotetext{
${ }^{12}$ Furthermore, it is significantly smaller in Low (Wald test: Low $+H i g h=0, p<0.0001$ ).

${ }^{13}$ In model (2) the base rate of acceptance is equal in the two treatments (Wald test: Low + High $=0$ $p=0.9848)$.
} 
Table 5: Explaining Acceptance, Inexperienced Subjects

\begin{tabular}{rcl}
\hline acceptance & $(1)$ & \multicolumn{1}{c}{$(2)$} \\
\hline Low & $-3.133^{* * *}$ & 0.670 \\
High & $-2.444^{* * *}$ & -0.847 \\
demand & & $-0.002^{* * *}$ \\
Low $\times$ demand & & $-0.001^{*}$ \\
High $\times$ demand & & $-18 \mathrm{e}-6$ \\
cons & $2.312^{* * *}$ & $17.792^{* * *}$ \\
\hline $\log N$ & \multicolumn{2}{c}{498} \\
$p$ model & $<0.001$
\end{tabular}

Note: Mixed effects logit estimation with random effects on subjects nested in group effects. Model 2 includes dummies for periods 2 to 8 (not reported). Significance: ${ }^{* * *} p<0.01,{ }^{* *} p<0.05,{ }^{*} p<0.10$.

all settings, but in treatment Low it decreases stronger than in the Baseline. ${ }^{14}$ This contradicts our expectation from hypothesis 4 that principals are more willing to concede a higher payoff for the agent in treatment Low.

Result 6 While principals pay higher wages in treatment Low (supporting hypothesis 4), they are not willing to concede more to the agent (contradicting it).

\subsection{Path Dependence}

In regulatory practice, if the regulator is convinced that another regime is preferable over the current, introducing the purportedly better rule requires regime change. Individuals who have gained experience with the previous regime are exposed to new rules. We have shown above that, for inexperienced subjects, honoring non-compete clauses does not affect effort as the NCC avoids efficiency losses if renegotiations fail. Principals and agents unequivocally benefit. It depends on the size of the statutory compensation whether principals or agents make more profit.

So, do choices and outcomes change when changing the regime? As Figure 5 shows, treatment effects on effort are pronounced. Descriptively, introducing non-compete clauses has a clear positive effect if compensation is High. This impression is already supported non-parametrically (signrank test, $\mathrm{N}=8, \mathrm{p}=.0251$ ). Interestingly, parametrically we also find that effort significantly increases, in comparison to a regime with Low compensation, if non-compete clauses are no longer enforced (linear mixed effects, $\mathrm{N}=1024$, coef $354.440, \mathrm{p}=.033)$.

\footnotetext{
$\overline{{ }^{14} \text { Joint hypothesis test } \quad \text { (Wald-test) }}$ model (2): $\quad$ demand + Low:demand $=0 \quad p \quad<\quad 0.001$; demand + High:demand $=0 p<0.001 ;$ Low:demand + High:demand $=0 p=0.195$.
} 


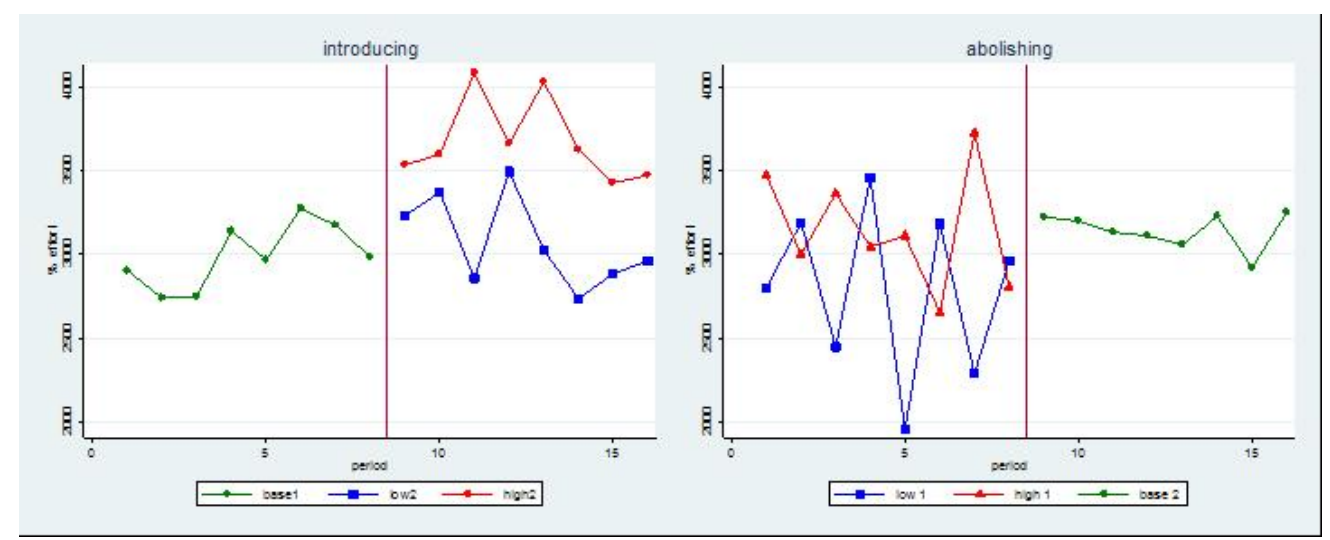

Figure 5: Effort, over time

Result 7 Introducing the enforcement of non-compete clauses increases effort if the compensation paid to agents is high. Abolishing the enforcement increases effort significantly if compensation was low.

Introducing non-compete clauses is less beneficial for the joint profit of both parties than one might have expected, given the clear positive effect on effort. Nonparametrically, we do not find a significant effect. Even parametrically, we only find a positive effect if compensation is High, and it is only weakly significant (linear mixed effects, $\mathrm{N}=1024$, coef. $824.635, \mathrm{p}=.070$ ). By contrast, abolishing a non-compete regime clearly reduces joint profit, irrespective of the size of the compensation (linear mixed effects, $\mathrm{N}=1024$, Low 1381.783, $\mathrm{p}=.002$; High 1021.025, $\mathrm{p}=0.022)$.

Result 8 Abolishing the enforcement of non-compete clauses reduces the joint profit of principals and agents, irrespective of the size of compensation.

This result is due to the substantial number of disagreements in the Baseline.

\section{Conclusion}

In this paper, we report first experimental results from introducing non-compete clauses to a stylized principal-agent model with probabilistic returns to non-contractible effort. Our main interest centers on the question how working efforts are affected by such non compete convenances in labor contracts, which allow employers to restrict the employee's freedom to leave the firm and compete with her former employer.

Our results show that working efforts are not affected by the presence of such clauses. We compare two treatments, one where statuary compensation for implementing a noncompete clause is High and one where it is Low, to a Baseline scenario without such a clause. Contrary to theoretical predictions, effort does not differ significantly between the three settings. This even holds if only a small compensation is paid to agents. In this 
situation, standard theory predicts a dramatic reduction of effort. In the experiment, inexperienced principals prevent this by voluntarily paying a substantial wage to insure their agent against the risk of project failure, and to induce higher effort. Agents in turn reciprocate higher wages with more effort. In other words, employer and employee manage to overcome the lack of incentives inherent to the Low compensation by other means. Newly introducing non-compete clauses does not reduce employee effort, even if statutory compensation is low.

While efforts do not differ, renegotiations in the Baseline often fail, which results in inefficiencies. We modeled these inefficiencies based on the intuition that the dissemination of an innovation to competitors will result in (fiercer) competition and consequently less industry profits. Drawing policy implications from this result, however, is impossible without including the demand side and, more specifically, consumer welfare, something we discuss in more detail below.

We therefore have a clear message. When assessing the pros and cons for non-compete clauses, employee incentives to invest effort should be a minor concern. As long as the statuary compensation is not extremely low, effort is unlikely to be affected as both sides of the labor market find other ways to create incentives. In the real world this result is likely to be stronger as, contrary to our simplified interaction, there are other contractual agreements possible which enhance worker incentives.

Turning to distributional aspects, policy makers need to consider the size of the statuary compensation. While joint profit of principals and agents are not affected, role specific profits are. With inexperienced subjects, honoring non-compete clauses even makes either party better off without reducing the other party's profit. If statutory compensation is low, principals gain and agents do not lose. If statutory compensation is high, agents gain and principals do not lose. With a regime change applied to experienced subjects, the distributional conflict looms larger. By the size of compensation, the legislator decides which side is going to gain from introducing a non-compete regime.

Like in all experimental studies, we had to abstract from many elements of real-life interaction between employers and employees. We already noted in the introduction that our design excludes direct investments by employers. In the experiment only agents invest into the success of the project. The only option for the principal is to pay a wage, and thereby to induce higher effort. In addition, interaction is anonymous and ad hoc, and participants are rematched every period. Employees are merely assigned to their employer. There is no labor market and hence no potentially adverse effect of noncompete clauses on labor mobility. Effort is not laborious, but simply a costly investment. If the project is successful, this simply means that total profit is higher. There is no creation of knowledge, and no personal attachment of workers to the knowledge they have created. Nor are fundamentally new products developed, which might lead to strategic disagreements between employer and employee, and possibly to welfare losses if the new product cannot be marketed through an entrepreneurial spin-off but is shelved (Klepper and Thompson, 2010). Successful innovation directly translates into higher profit. There is thus no opposite market side, and no market risk. In the Baseline, if negotiations fail, this directly implies a smaller profit for either party, ignoring the possibility for (implicit) collusion in the real world. Finally, in the treatments with non-compete clauses these 
are automatically imposed. The principal neither has the possibility to hire without this clause, nor to waive the clause if the project succeeds.

In future work, at least some of these aspects might be translated into additional treatments. Yet we believe that our design captures the essence of the normative problem. Are principal and agent better or worse off if the principal may write a contract that prevents the agent from competing with her if the agent's efforts lead to innovation, or to an extension of the customer base? As it turns out, giving the principal this power never reduces effort, even with experienced subjects. Society may still dislike non-compete clauses. One plausible argument is distributional. Yet our experiment shows that, in line with standard theory, the distributional effects hinge on the size of the statutory compensation, and that there may even be room for a straightforward Pareto improvement. It is also conceivable that the enforcement of non-compete clauses substantially reduces the intensity of competition in individual markets. Another plausible argument only affects innovation, not an extension of the customer base. While effort is not reduced, and therefore innovation is not less likely, successful employees are prevented from leaving the firm, and the new knowledge will spread less rapidly. As originally suggested by Gilson (1999), this might have adverse effects on industry evolution if embodied knowledge transfers are substantial. At any rate, given our findings, a key argument against enforcing non-compete clauses is not valid: the agent's effort is not reduced.

\section{References}

Belenzon, S. and M. A. Schankerman (2012). Spreading the word: Geography, policy and university knowledge diffusion. The Review of Economics and Statistics EI50. forthcoming.

Berg, J., J. Dickhaut, and K. Mc Cabe (1995). Trust, reciprocity, and social history. Games and Economic Behavior 10, 122-142.

Brandts, J. and G. Charness (2004). Do labour market conditions affect gift exchange? some experimental evidence. The Economic Journal 114, 684-708.

Camerer, C. F. (2003). Behavioral Game Theory - Experiments in Strategic Interaction. Princeton University Press.

Charness, G. (2000). Self-serving cheap talk. a test of aumann's conjecture. Games and Economic Behavior 33, 177-194.

Cooper, D. J. and J. H. Kagel (2013). Handbook of Experimental Economics, Vol 2, (eds), Volume 2, Chapter Other-Regarding Preferences: A Selective Survey of Experimental Results. Princeton University Press. mimeo.

Fallick, B., C. A. Fleischman, and J. B. Rebitzer (2006). Job-hopping in silicon valley. some evidence concerning the microfoundations of a high-technology cluster. Review of Economics and Statistics 88(3), 472-481. 
Fehr, E., G. Kirchsteiger, and A. Riedl (1993). Does fairness prevent market clearing? an experimental investigation. The Quarterly Journal of Economics 108(2), 437-459.

Fischbacher, U. (2007). z-Tree: Zurich toolbox for ready-made economic experiments. Experimental Economics 10(2), 171-178. The experiment was programmed and conducted with the software z-Tree (Fischbacher 2007).

Franco, A. M. and M. F. Mitchell (2008). Covenants not to compete, labor mobility, and industry dynamics. Journal of Economics 83 Management Strategy 17(3), 581-606.

Garmaise, M. J. (2011). Ties that truly bind: Noncompetition agreements, executive compensation, and firm investment. Journal of Law, Economics, and Organization $27(2), 376-425$.

Gilson, R. J. (1999). The legal infrastructure of high technology industrial districts: Silicon valley, route 128, and covenants not to compete. New York University Law Review 7/, 575-629.

Greiner, B. (2004). An online recruitment system for economic experiments. In K. Kremer and V. Macho (Eds.), Forschung und wissenschaftliches Rechnen 2003, Volume 63 of GWDG Bericht. Göttingen: Gesellschaft für Wissenschaftliche Datenverarbeitung.

Ingram, J. D. (2002). Covenants not to compete. Akron Law Review 36, 49-79.

Klepper, S. and P. Thompson (2010). Disagreements and intra-industry spinoffs. International Journal of Industrial Organization 28(5), 526 - 538.

Kreps, D. M. and R. Wilson (1982, Jul). Sequential equilibria. Econometrica 50(4), 863-894.

Kräkel, M. and D. Sliwka (2009). Should you allow your employee to become your competitor? on noncompete agreements in employment contracts. International Economic Review 50(1), 117-141.

Marx, M., D. Strumsky, and L. Fleming (2009). Mobility, skills, and the michigan non-compete experiment. Management Science 55(6), 875-889.

Montero, M., M. Sefton, and P. Zhang (2008). Enlargement and the balance of power. an experimental study. Social Choice 83 Welfare 30, 69-87.

Samila, S. and O. Sorenson (2011). Noncompete covenants: Incentives to innovate or impediments to growth. Management Science 57(3), 425-438.

Stuart, T. and O. Sorenson (2003). The geography of opportunity: spatial heterogeneity in founding rates and the performance of biotechnology firms. Research Policy 32(2), $229-253$.

Tversky, A. and D. Kahneman (1992). Advances in prospect theory: Cumulative representation of uncertainty. Journal of Risk and Uncertainty 5, 297-323. 10.1007/BF00122574. 
Whitmore, P. J. (1989). Statistical analysis of noncompetition clauses in employment contracts. Journal of Corporation Law 15, 483-533.

\section{A. Translation of Instructions}

The following is a translation of the German instructions for the sessions in which participants first faced the baseline. Whenever the instructions in the other sessions differed, we indicate this by putting the differing text in parentheses and preceding it by "N-B:".

\section{Instructions}

Welcome! We would ask you please to communicate no longer with the other participants, and to switch off your mobile phone. In the following experiment, you can earn money, which is why we would ask you please to read these instructions very carefully. If anything is unclear to you, please don't call out, but raise your hand and wait for someone to come to you. The instructions are identical for all participants. You shall remain anonymous in this experiment. This means no participant will be told your identity by us.

There are two different roles. Half of the participants make their decisions in role A, while the other half have role B. The roles are randomly assigned at the beginning, and you keep your assigned role throughout the entire experiment. In total, the experiment consists of two sections. Each section, in turn, consists of eight rounds. For each section, you will receive new instructions. How you behave in a round or section has no effect whatsoever on the proceedings in any of the following rounds or sections.

During the experiment, all sums of money will be calculated in Taler. You can earn money in each round - but it is also possible to lose money. How much money you earn depends on your decisions, on the decisions made by the participant assigned to you, and on random draws. In each section, however, only the money earned in one single round is paid out to you: At the end of the experiment, a draw determines which round per section is relevant for the calculation of the payoff of all participants (there is one independent draw per section). For each participant in the experiment, the payoff is calculated from the sums reached in these two rounds that have been drawn. The payoff earned by you in the experiment, in Taler, is converted into €at the end of the experiment and paid to you in cash at the rate of 1000 Taler $=€ 1.40$.

Further, you will receive the sum of $€ 2.50$ for showing up punctually. At the beginning of each section, you will be given a questionnaire with control questions, and an additional $€ 2.00$ for each questionnaire you have filled in. Should you incur losses during the experiment, these will be subtracted from your other payments. Should you not be in a position to balance your losses from the experiment, you have two options: Either you pay for the difference by working it off (counting the frequency of a letter in a text), or else you pay out of your own pocket. 


\section{Part 1}

In each of the following eight rounds, you will interact with another participant who will be randomly matched with you in the other role. In this section, you will interact no more than once with anyone.

1. A decides on a fixed payment $f$ for $B$, which can lie anywhere between 0 and 10,000. $B$ definitely receives this fixed payment, regardless of how the round progresses.

2. $B$ is told the sum of payment $\mathrm{f}$ and decides how much to invest in a project that potentially harbors high winnings. This investment e, which can lie anywhere between 1 and 6,000, costs $B$ exactly the sum e and is subtracted from $B$ 's payoff.

3. The amount of investment e determines the probability of a project being successful. With probability $w=\sqrt{e} / 100$ it will be successful; with probability $1-w=1-\sqrt{e} / 100$ it will not be successful: The more $B$ invests, the more probable success is (see Figure 1). Only $B$ knows the amount of his or her investment $e$. Participant $A$ is never informed about it.

In each round, participants $A$ and $B$ successively make the following decisions.

A random draw therefore determines, with probability $\mathrm{w}$, whether the project is successful.

- If the project is not successful, the round ends and $A$ receives: $4,000-f$

$B$ receives: $f-e$

- If the project is successful, $B$ has the opportunity to demand a further payment $v$ from $A$.

a) $B$ determines the demand $v$ (any sum between 0 and 18,000).

b) $A$ is told how much $B$ is demanding and decides whether to accept or decline. The round ends with the following payments:

* If participant $A$ accepts participant $B$ 's demand $v$, the round ends as follows:

$A$ receives: $18,000-f-v B$ receives: $f+v-e$

* If participant $A$ declines participant $B$ 's demand $v$, the total payoff from the successful project is reduced, and the round ends as follows: $A$ receives: $6,000-f B$ receives: $6,000+f-e$

( N-B: If participant $A$ declines participant $B$ 's demand $v$, the round ends as follows:

$A$ receives: $18,000-K-f$

$B$ receives: $K+f-e)$ 
(N-B: The sum $K$ is determined at the beginning of a round, and both participants ( $A$ and B) are informed about it. This sum can be either 7,000 or 12,000 Taler.)

The diagram in Figure 2 illustrates how a round proceeds.

You will now receive a questionnaire with control questions, which we use to ensure that all participants have understood the instructions. Should you have any questions, you may contact a supervisor at any time. You will receive $€ 2.00$ for answering the questionnaire. 
Figure 1: Probability $w$

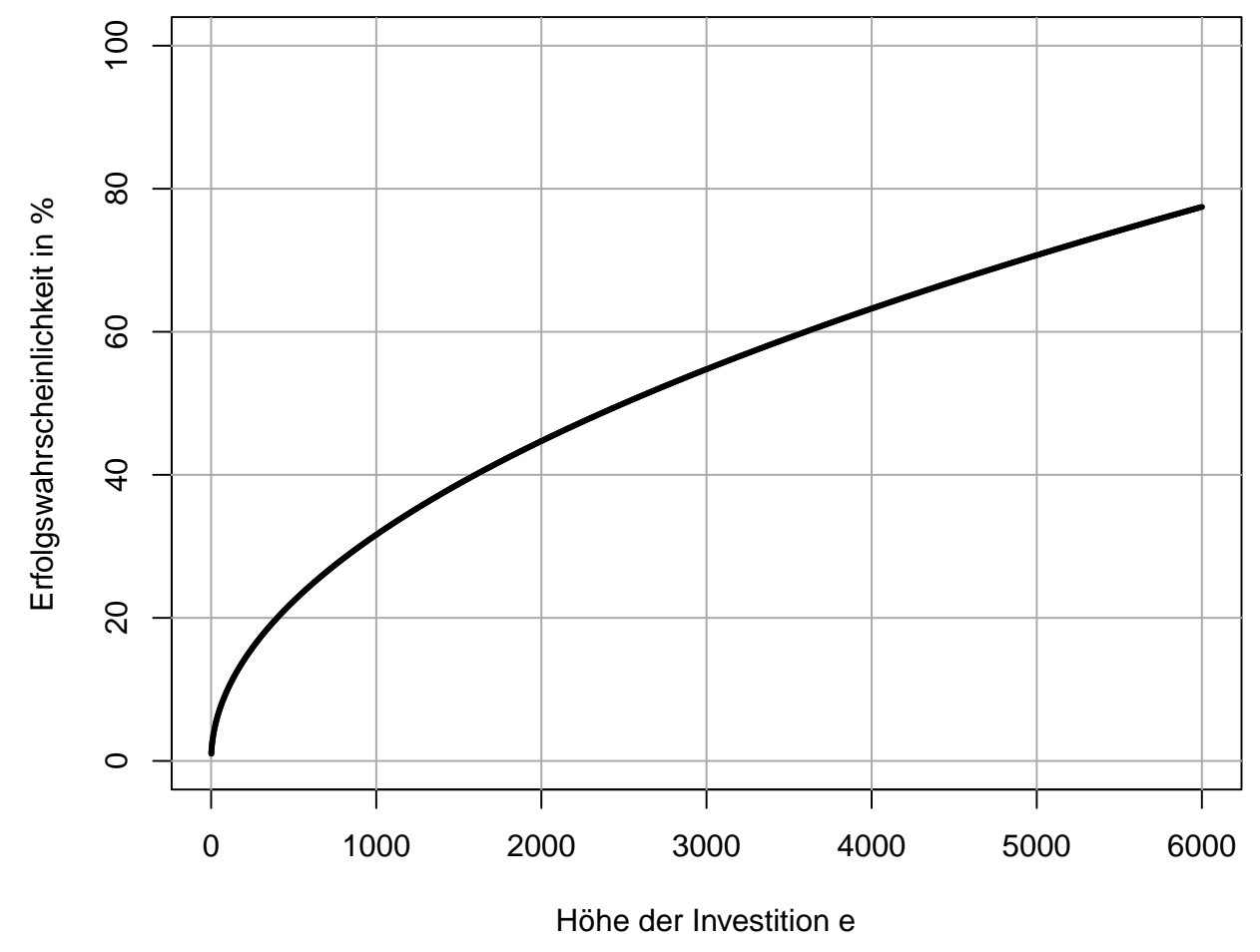

\section{Part 2}

In each of the following eight rounds, you will interact with another participant who will be randomly matched with you in the other role. In this section, you will interact no more than once with anyone.

In each round, both participants make the same decisions as before. The only difference is that the payoffs change, in case of success and in case of $A$ declining demand $v$ :

So, if the project is successful, $B$ once again has the opportunity, as before, to demand a further payment $v$ from $A$ :

a) $B$ determines the demand $v$ (any sum between 0 and 18,000).

b) $A$ is told how much $B$ is demanding and decides whether to accept or decline. The round ends with the following payments:

- If participant $A$ accepts participant $B$ 's demand $v$, the round ends and $A$ receives: $18,000-f-v$

$B$ receives: $f+v-e$ 
Figure 2: Timeline of a round

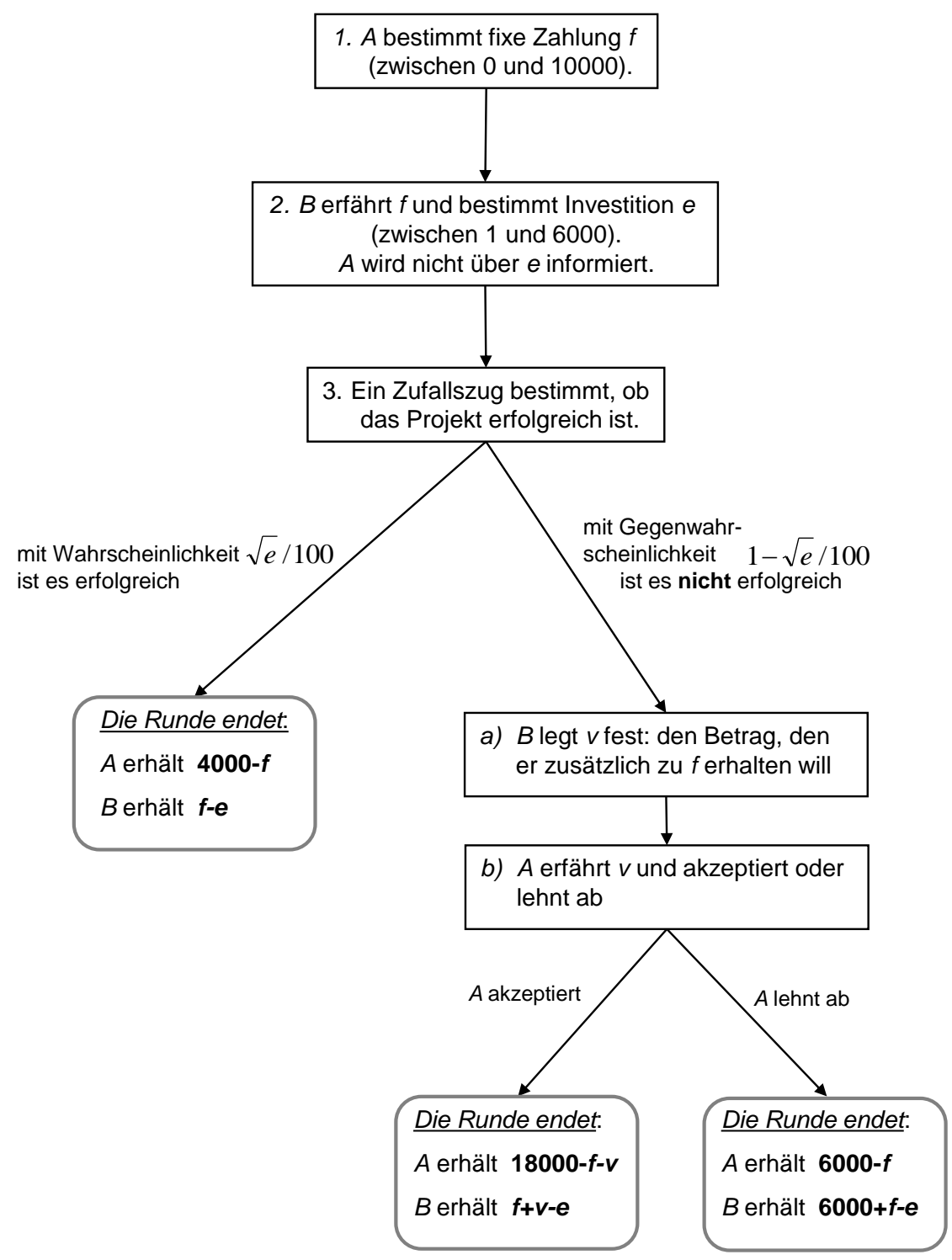

(N-B: see Figure 3 below.) 
- If participant $A$ declines participant $B$ 's demand $v$, then $A$ receives: $18,000-K-f$

$B$ receives: $K+f-e$

( N-B: If participant A declines participant B's demand $v$, the total payoff from the successful project is reduced, and the round ends as follows:

$A$ receives: 6.000- $f$

$B$ receives: $6.000+f-e$.

The sum $K$ is determined at the beginning of a round, and both participants ( $A$ and $B$ ) are informed about it. This sum can be either 7,000 or 12,000 Taler. (N-B: paragraph deleted.)

The timeline in Figure 3 will give you an idea of how a round progresses. You will now receive a questionnaire with control questions, which we use to ensure that all participants have understood the instructions. Should you have any questions, you may contact a supervisor at any time. You will receive $€ 2.00$ for answering the questionnaire. 
Figure 3: Timeline of a round

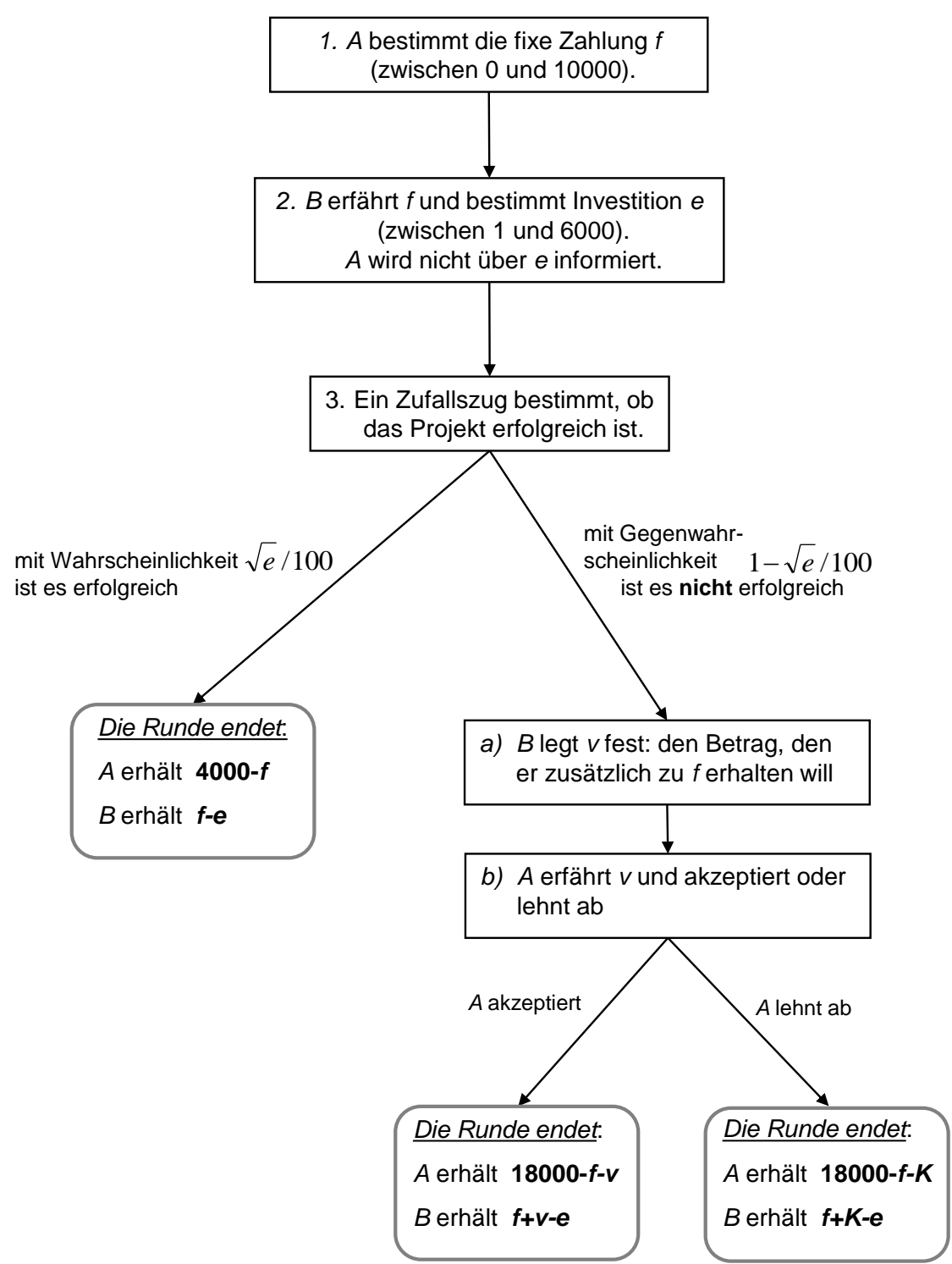

(N-B: see Figure 2.) 